\title{
Art Therapy to Improve Quality of Life of Cancer Patients and Their Carers in Bangladesh
}

\author{
Rumana Dowla1 ${ }^{*}$, Annekathryn Goodman², Tahsin Kashem ${ }^{3}$ \\ ${ }^{1}$ Bangladesh Palliative and Supportive Care Foundation, Bangabandhu Sheikh Mujib Medical University and Hospital (BSMMU), \\ Dhaka, Bangladesh \\ ${ }^{2}$ Division of Gynecologic Oncology Massachusetts General Hospital, Boston, MA, USA \\ ${ }^{3}$ Bangladesh Palliative and Supportive Care Foundation, Dhaka, Bangladesh \\ Email: ^rumanadowla@hotmail.com, agoodman@mgh.harvard.edu, Tahsin.Kashem@gmail.com
}

How to cite this paper: Dowla, R., Goodman, A. and Kashem, T. (2019) Art Therapy to Improve Quality of Life of Cancer Patients and Their Carers in Bangladesh. Journal of Cancer Therapy, 10, 457-469.

https://doi.org/10.4236/jct.2019.106038

Received: May 8, 2019

Accepted: June 21, 2019

Published: June 24, 2019

Copyright $\odot 2019$ by author(s) and Scientific Research Publishing Inc. This work is licensed under the Creative Commons Attribution International License (CC BY 4.0).

http://creativecommons.org/licenses/by/4.0/

(c) (i) Open Access

\begin{abstract}
Objective: Art as a therapy helps in reparation and recovery. The aim of this study was to see the response of the cancer patients and their carers residing in Bangladesh towards art therapy and the perceived effect of art therapy on their physical and psychological condition. Method: The study was a record review study conducted through a cross-sectional descriptive method from July to November 2018. Along with the cancer patients, their immediate carers were enrolled in this study since patients and their carers both suffer from the distress that comes with the diagnosis of cancer. In-depth interviews and focused group discussions of art therapy were conducted with our study population at BPSCF and BSMMU. Findings: After art therapy, there was an improvement in sensory perception and self-perception, physical and psychological condition, communication and social skills and helped in more personal integration and built stronger insight among the patients and carers. Majority of the participants of art therapy felt good and wanted to continue art therapy. Significance of results: The results of this study will help to create awareness among the community about the importance of psychotherapies like art therapy in the life of the cancer patients and their carers. Introducing the concept of art therapy will also help the public health practitioners to improvise palliative care services in Bangladesh in a very cost-effective approach.
\end{abstract}

\section{Keywords}

Art Therapy, Cancer Care, Quality of Life, Bangladesh

\section{Introduction}

Art therapy (AT) can be described as a form of art making, a mode of nonverbal 
communication of feelings and thoughts which facilitates reparation and recovery [1]. AT engages the body, mind and soul through an integrative method in such a distinct manner that verbal articulation solely cannot adopt [2]. The American Art Therapy Association defines art therapy, a profession, as "an integrative mental health and human services profession that enriches the lives of individuals, families, and communities through active art-making, creative process, applied psychological theory, and human experience within a psychotherapeutic relationship" [2]. AT includes drawing, painting, photography, sculpture and other forms of visual art expression [3].

AT increases self-esteem and self-awareness, improves cognitive and sensorimotor functions, reduces mental and emotional distress, enhances social skills, develops positive coping strategies, increases quality of life, reduces experiences in physical pain and enhances emotional resilience [2] [4]. On the other hand, for the carers, AT in a palliative setting, helps in the bereavement [4]. AT involves use of art materials to explore and express feelings, thoughts and other personal issues that might have been repressed [4]. The repressed feelings may include anger, sadness, envy and fear for upsetting the near ones [4]. It also allows expressing positive feelings like hope, beauty or tenderness [4]. In simple words, art therapy can help to nurture positive feelings and also reflect on negative or difficult thoughts [5].

AT can help to explore deeper feelings and also helps in dealing with their cancer experience [5]. In 2015, 8.8 million people died because of cancer making it a second leading cause of death globally [6]. In low- and middle-income countries, approximately $70 \%$ of deaths occur from cancer [6]. In Bangladesh, 12.7 million deaths accounted for cancer leading to a need for palliative care to reduce suffering and disability worldwide [6]. The total estimated economic cost of cancer was approximately US $\$ 1.16$ trillion in 2010 showing an increase in the economic burden [6]. As a psychosocial palliative care intervention, art-making projects can foster positive interaction between patients and nurses [7]. Art-making projects when exposed to the children suffering from childhood cancer can give an opportunity to the parents to get involved with their child in art making and can ease the situation during oncology treatments [7].

AT is considered as a health profession which is state registered in countries like Canada, United States, Australia, United Kingdom and other European countries [4]. In UK, a recent survey showed that in the palliative phase, over $50 \%$ of the art therapists have been working with adult cancer care people [4]. A study done in 2011 with art therapists and service users in UK showed that among 55 service users (adults with cancer), 92\% of which agreed that it benefited coping, provided new perspectives, facilitated expression of feelings and assisted distraction from worries [8].

A study done in Taiwan shows that during art therapy, 53\% of the patients felt much better or very much better physically, whereas $70 \%$ of the terminal cancer patients felt much relaxed or very much relaxed emotionally [9]. Within a pallia- 
tive context, another study showed that art therapy helped in reducing distress which included symptoms like pain, anxiety, ill-being, depression, sadness and tiredness [10]. This study was conducted with 28 patients who participated in 63 sessions of art therapy [10].

In Bangladesh, Canadian activist Fahmida Urmi Hossain has introduced art as a therapy to heal trauma to improve the mental health condition of women. ${ }^{11}$ Acid Survivors Foundation organized a three-day-long art therapy workshop conducted by Fahmida Urmi Hossain, where 8 acid survivors attended for their mental and emotional well-being [11]. In Bangladesh in 2016 doctors without borders introduced art therapy among the Sexual and Gender-based Violence (SGBV) survivors in Kamrangirchar slums [12].

There is little empirical evidence that shows the efficacy of AT and there has not been much discussion on the sole effects of AT [3] [13]. Moreover, the detailed description of art therapy was not provided by many studies [13]. AT has been practiced in Bangladesh recently but no literature exists to show the benefits of art therapy except few newspaper articles [11] [12].

The aim of this study is to understand how patients and carers responded to art therapy and explore their unexpressed emotion. The objective of this study was also to understand the perceived effects of AT on the physical and psychological condition of the participants. In addition to the existing literatures, this study could give a complete image about the benefits of AT among the cancer patients and their carers. This study will help to increase awareness about such psychotherapies in Bangladesh among the community and public health practitioners. Moreover, this study will give a lead to the theoretical formation of art therapy in Bangladesh context.

\section{Materials and Methods}

The study was conducted through a cross-sectional descriptive approach, which included a record review from July to November 2018. This study was conducted from the records of Bangladesh Palliative and Supportive Care Foundation (BPSCF) in Dhaka, Bangladesh. Work was done at both the Bangladesh Palliative and Supportive Care Foundation (BPSCF) and Bangabamdhu Sheikh Mujib Medical University and Hospital (BSMMU). The ethics boards at both institutions approved the study. A quantitative descriptive approach was used to identify the socio-demographic information of the patients and their carers, whereas qualitative exploratory approach based on Maxwell iterative model was used to explore the art therapy effect and the perspectives about art therapy.

All the patients having cancer who were admitted to the palliative wards of BPSCF and Bangabandhu Sheikh Mujib Medical University (BSMMU) from January to February in 2018 and their immediate carers who stayed with the patients in the hospital or foundation, participating in the art therapy sessions named "Healing through Art" conducted by BPSCF were included in this study. 
Inclusion criteria: Patients and participants with an age $\geq 18$ years and patients diagnosed with cancer who were able to communicate and had ECOG $\leq 3$ were included in this study.

Exclusion criteria: Patients who were less than 18 years of age, could not consent, or had a performance status of 4 were excluded from this study.

The session "Healing through Art" was an hour art therapy session where the participants were given art supplies like drawing books, crayons, pencil and eraser by BPSCF. Through purposive sampling data was collected from a total of 27 participants. Guest, Bunce and Johnson (2006) founded with their data set that data saturation can be obtained within first 12 interviews for a particular group [14]. With reference to this, our study focused data of 12 patients and 12 carers but data collection continued until data saturation.

Documents and photographs of their art were collected from the stored soft copies from electronic devices of BPSCF. The data of our study were collected from semi-structured questionnaires, in-depth interviews (IDIs) and focused group discussion (FGDs) guidelines which were used by BPSCF in the interview with the participants. Mobile devices were used to scan the pictures that the participants' had drawn.

To check the reliability, the study tools were reviewed among the peers. Any issues found in the questionnaire and guidelines was edited and corrected accordingly by the research investigators. Prior permission was taken from BPSCF and BSMMU authority before data collection to conduct the study with their records. This study was ethically approved by Bangladesh Medical Research Council (BMRC).

The collected data were reviewed by the research investigators to ensure the accuracy of data. After data familiarization, data displays and data memos were developed for qualitative data. A-priori codes and inductive codes were developed and modified while coding after collecting the data of January to February 2018. After coding data, clustering and comparing, patterns and themes identification was done. This was an iterative process and involved multiple analysis and repetitions. Peer review was done throughout the procedure to minimize the errors. Conclusions were drawn following that along with verification and triangulation where other literatures were used as sources to ensure the reliability of the study. The data entry and descriptive analysis of the socio-demographic data were done through STATA version 13.

\section{Findings and Discussion}

\subsection{Background of the Participants}

Table 1 presents information on the socio-demographic characteristics of the participants. A total of 27 respondents participated in the art therapy (AT) named "Healing through art" showed. Among them, 15 respondents were patients who had cancer and 12 respondents were their carers. Male participants (40.7\%) were less than female participants (59.3\%). The majority $(59.3 \%)$ of the participants 
Table 1. Socio-demographic characteristics of participants.

\begin{tabular}{|c|c|c|}
\hline Characteristics & Frequency $(\mathrm{N})$ & Percent (\%) \\
\hline \multicolumn{3}{|l|}{ Type of Participants } \\
\hline Patient & 15 & 55.6 \\
\hline Carer & 12 & 44.4 \\
\hline Total & 27 & 100.0 \\
\hline \multicolumn{3}{|l|}{ Sex } \\
\hline Male & 11 & 40.7 \\
\hline Female & 16 & 59.3 \\
\hline \multicolumn{3}{|l|}{ Age (Years) } \\
\hline$<25$ & 4 & 14.8 \\
\hline $25-49$ & 16 & 59.3 \\
\hline$\geq 50$ & 7 & 25.9 \\
\hline \multicolumn{3}{|l|}{ Marital Status } \\
\hline Single & 5 & 18.5 \\
\hline Married & 19 & 70.4 \\
\hline Widowed & 3 & 11.1 \\
\hline \multicolumn{3}{|l|}{ Level of Education } \\
\hline No formal education & 6 & 22.2 \\
\hline Primary ${ }^{a}$ incomplete & 5 & 18.5 \\
\hline Primary complete & 2 & 7.4 \\
\hline Secondary incomplete & 3 & 11.1 \\
\hline Secondary complete or higher & 11 & 40.7 \\
\hline \multicolumn{3}{|l|}{ Religion } \\
\hline Islam & 25 & 92.6 \\
\hline Christian & 2 & 7.4 \\
\hline \multicolumn{3}{|l|}{ Occupation } \\
\hline Unemployed & 1 & 3.7 \\
\hline Homemaker & 14 & 51.9 \\
\hline Farmer & 4 & 14.8 \\
\hline Private Job & 3 & 11.1 \\
\hline Health Counselor & 2 & 7.4 \\
\hline Nurse & 2 & 7.4 \\
\hline Student & 1 & 3.7 \\
\hline \multicolumn{3}{|l|}{ Annual HH Income (BDT) $)^{b}$} \\
\hline$<6000$ & 2 & 7.4 \\
\hline $6000-14,999$ & 15 & 55.6 \\
\hline$\geq 15,000$ & 10 & 37.0 \\
\hline Mean $( \pm \mathrm{SD})$ & $94,740.8( \pm 156,388)$ & \\
\hline
\end{tabular}

aPrimary complete refers to schooling up to Class 5, Secondary complete refers to schooling up to Class 10 . ${ }^{\mathrm{b}} 1 \mathrm{USD}=84.4$ BDT. 
belonged to the age group 25 - 49 and most of them (70.4\%) were married. The average annual household income was 94,740.8 $( \pm 156,388)$ BDT where most (55.6\%) of them had an income range between 6000 - 14,999 BDT.

The majority (51.9\%) of participants were homemakers (Figure 1) as most (59.3\%) of the participants were female (Table 1 ) whereas around $14.8 \%$ of them were farmers (Figure 1). Among the carers 16.7\% were health counselors and $16.7 \%$ were nurses but the majority $(60 \%)$ of carers were homemakers displayed in Figure 1. The majority $(41.7 \%)$ of the patients were homemaker who did household chores mostly and around $6.7 \%$ of them were unemployed as they had to leave their jobs because of the disease. $8.3 \%$ had private jobs which included business, tutoring and private company jobs.

Table 2 shows the condition of the patients who participated in the art therapy

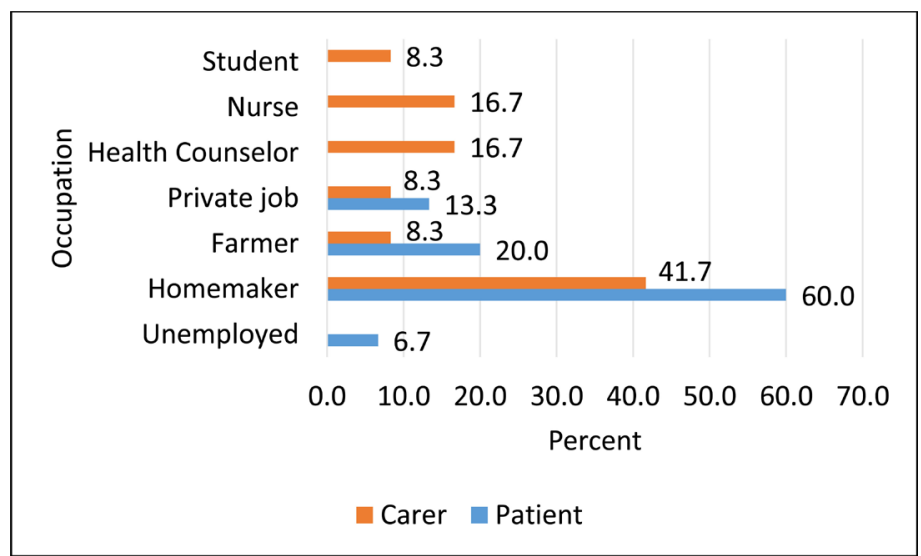

Figure 1. Occupation of the participants of "Healing through art".

Table 2. Patient's profile.

\begin{tabular}{|c|c|c|}
\hline Condition & Frequency $(\mathrm{N})$ & Percent (\%) \\
\hline \multicolumn{3}{|l|}{ Type of Cancer } \\
\hline Ca, Cervix & 3 & 20.0 \\
\hline $\mathrm{Ca}$, Rectum & 3 & 20.0 \\
\hline Ca, Larynx & 1 & 6.7 \\
\hline Ca, Stomach & 2 & 13.3 \\
\hline $\mathrm{Ca}$, Uterine & 1 & 6.7 \\
\hline Lt Nasal Cavity & 1 & 6.7 \\
\hline Synovial Sarcoma & 1 & 6.7 \\
\hline Left buccal mucosa & 1 & 6.7 \\
\hline Ca Bot ē MNN & 1 & 6.7 \\
\hline D. Laryngeal growth squamous cell carcinoma grade II & 1 & 6.7 \\
\hline \multicolumn{3}{|l|}{ ECOG Status } \\
\hline 1 & 4 & 26.7 \\
\hline 2 & 8 & 53.3 \\
\hline 3 & 3 & 20.0 \\
\hline
\end{tabular}


which includes the type of cancer they have been suffering and their ECOG status. $20 \%$ of the patients had cervix cancer, $20 \%$ had rectum cancer whereas $13.3 \%$ of them had stomach cancer. The majority $(53.3 \%)$ of them belong to the ECOG grade 2 where they were capable of self-care but were unable to do their activities up and above more than $50 \%$ of their waking hours.

\subsection{Effects of Art therapy}

The majority (80\%) of the patients and almost all the carers mentioned after art therapy (AT) that they felt good during the therapy (Figure 1). Only a few (13.3\%) patients mentioned that they felt really good but $6.7 \%$ of the patients did not feel good during the therapy AT (Figure 2).

\subsubsection{Improved Sensory Perception and Self Perception}

Perception is the core of the effects of AT which was experienced by the patients and their carers. It includes discovering the art supplies, reflecting on the materials, exploring choices and possibilities, feeling the following physical and emotional effects resulting in intensified self-awareness and a sense of individuality. Through AT they were able to experience their immediate emotional responses while drawing and perceived the body signals during and after drawing the pictures. While all the carers enjoyed drawing the pictures, 3 out of 15 patients mentioned they got tired after drawing and 1 patient felt weak after drawing. Patients and carers who participated in the therapy not only expressed their feelings and also understood other's feelings that came with the disease. Moreover, participants perceived that few patients were weak and had difficulty with the art supplies,

"Well, most of them said that they did not have that much difficulty. But some mentioned that the crayons were a bit hard for them to hold for their weak hands." (IDI 21, a 34-year-aged female, Nurse)

A study with patients diagnosed with personality disorders showed that participants perceived that working with art can lead to more physical and emotional awareness. [3] Our study also showed that patients were able to understand their physical and emotional responses.

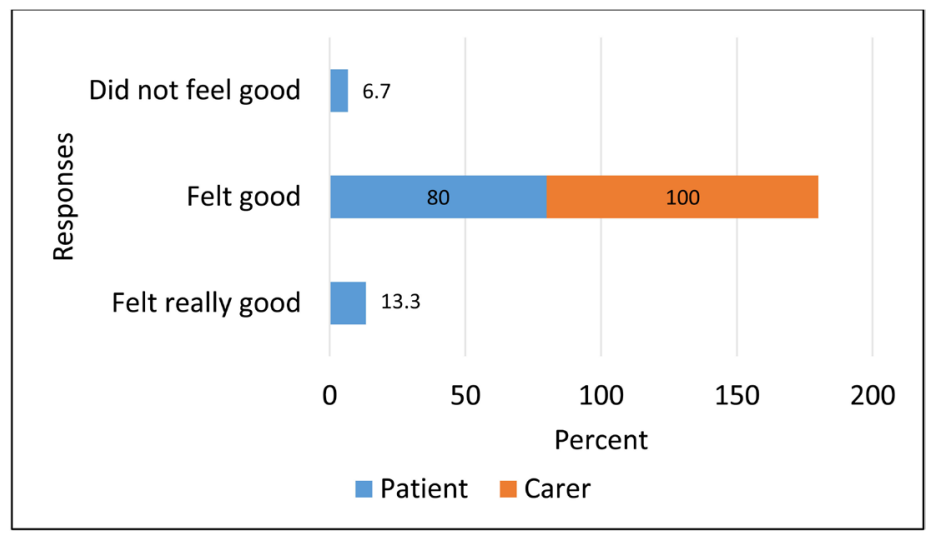

Figure 2. Responses towards art therapy. 


\subsubsection{Improved Health}

Health concerns the state of complete physical and psychological well-being experienced by the participants. While few patients felt weak, participants responded that there was a contribution of AT towards the physical condition of the patients and reduction in mental distresses of both the patients and carers. After drawing and talking about the drawn pictures, the majority (13 out of 25 participants) stated that it helped in reducing distresses like stress, tension, anger and anxiety which comprises the psychological distresses of the patient and carers that comes with cancer. AT helped to forget physical and emotional distresses for a while, one of the participants having cancer mentioned,

"I felt good in this art session. I was very tired. But I did not feel that tiredness while I was drawing. It made me think about the things I like and draw the pictures of those things." (IDI 04, a 65-year-aged female, Homemaker)

Both formal and informal carers were able to bring forward their emotions through art and hence mentioned that drawing pictures helps them to reduce their stress and worried thoughts. On the other hand, 1 patient out of total 25 participants mentioned that it helped in improving the existing physical condition. One of the carers also mentioned about her patient,

"He had fever from last two days... Although it was difficult for him to draw as he had less strength in his hand but he drew the art seeing me. I think drawing helped him to recover from fever faster." (IDI 16, a 40-year-aged female, Homemaker)

However, in the study conducted in Taiwan showed that the majority of patients (53.1\%) mentioned that there was an improvement in physical condition [9]. In a pilot study done in a hospital's oncology unit, participants reported improvement in tiredness, anxiety, pain, depression consistent to our study along with other symptoms like drowsiness, lack of appetite, wellbeing and shortness of breath [15]. Creative art interventions also reduce stress, lowers anxiety and negative emotions consistent with our findings [16].

\subsubsection{Improved Communication and Social Skills}

Communication involves verbal and non-verbal way of expressing the emotions and which brought a change in the behavior of the patients towards themselves and also towards others. Cooperating with one another through social interaction the participants helped out each other to come up with art and openly discuss their feelings that they felt during the journey of the disease. 2 out of 25 participants mentioned that they helped the patients to draw some pictures while they explained verbally or non-verbally what they wanted to draw since they were feeling weak. A number of participants (13 out of 25 participants) stated that they shared their stories of disease with one another during the AT session which helped them to related with each other. Indications were there that patients and their carer learned to find social support from the fellow participants. While sharing their stories of the disease they developed building self-respect to accept their condition. One of the respondents mentioned, 
"After coming to this art session, I have seen that I am not alone with this disease. There are people like me who are also facing the same situation. We have all talked about our condition during the art session." (FGD 01, a 20-year-aged male, Home Tutor)

Few patients stated that they changed their behavior and started drawing after seeing others draw which worked as a motivation for them. Not only patients but also carers got motivated by seeing others and started drawing apart from motivating patients to draw. One of the carers stated,

"I started drawing pictures so that the patients could see me drawing and feel motivated enough to start drawing. I have seen that it actually works." (FGD 15, a 60-year-aged female, Nurse)

While in our study some carers helped patients to draw, another pilot study also showed when patients found the art materials difficult to use, the therapists helped them to form the art [15]. The study with personality disorder patients showed that they got social support from other participants of AT, looked for a solution together and learned to change their behavior patterns [3]. Art was regarded as a communication tool as it improved the way of communication of cancer patients [17].

\subsubsection{More Personal Integration}

Personal integration concerns the integration of diversified polarities in oneself resulting in more self-acceptance and self-coherence. Through AT patients and carers expressed their personal issues, portrayed emotional experiences and identified self-image or lifestyle. 11 out of 25 participants mentioned that after identifying their likings they drew the pictures of objects, places or activity that they like. On the other hand, 10 out of 25 participants mostly drew landscape pictures of their village house or surrounding environment near their village house consisting of flowers, river, boat, fishes and so on whereas some participants (4 out of 25) drew pictures of activities reflecting on their personal lifestyle. Some of them also mentioned about the loss that they have to face due to the cost of treatment for cancer like selling assets and also reflected about the worry that they have to bear because of the cost. The following image shows a picture where a patient portrayed her life after getting affected with the disease after accepting herself and her inner conflicts. Figure 3 shows an example of this.

More self-coherence and personal integration were facilitated through their inner conflicting feelings and thoughts. The patients and carers also reflect on their past and recent memories through their art. They explored, recognized and acknowledged the emotions portraying their memories. The following quote reflects this integration process and the picture shows flowers around the Bangla word "Ma" (Mother).

Art creation process helps a patient to develop ideas and express his/her feelings [18] [19]. Figure 4 shows an example of this. In a study of Taiwan, patients mostly drew pictures of landscape which is consistent with our study too [9]. Unlike our study, patients having personality disorder reflected their inner 


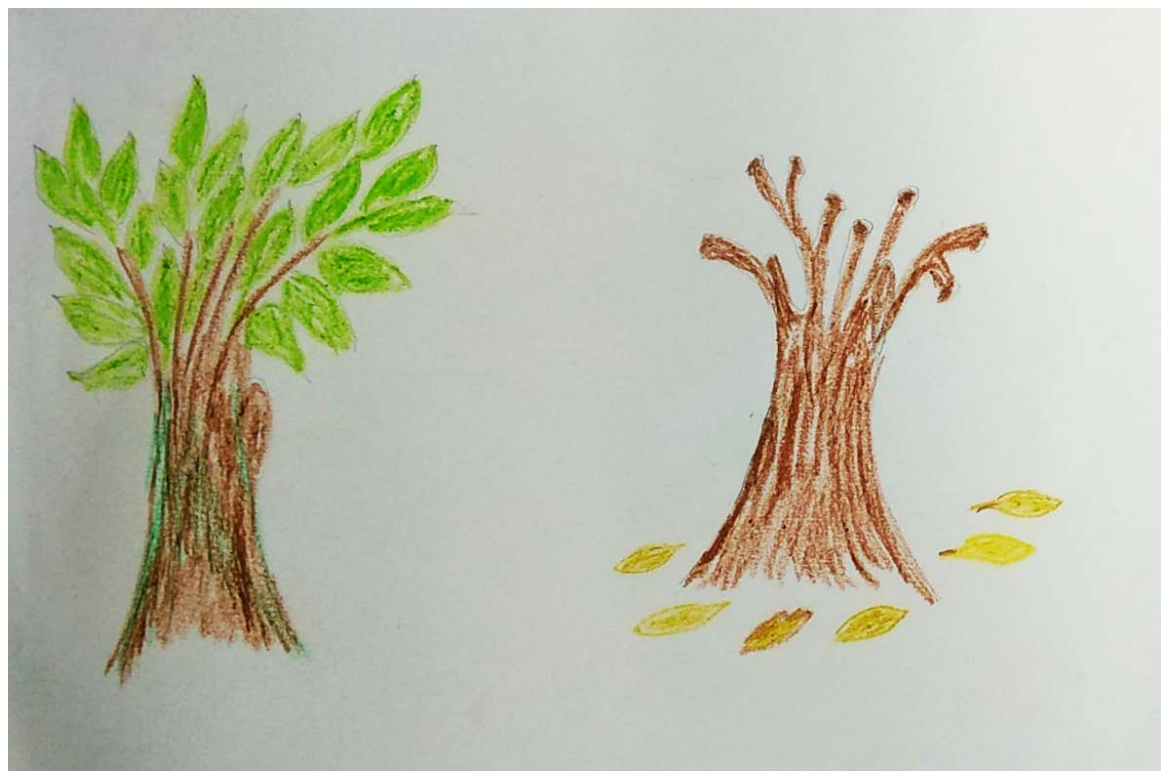

Figure 3. An example of loss expressed in art. "The way I felt active in the early parts of my life, now I do not feel active. I used to enjoy my life a lot but now it is all in vain...I know my condition is worsening. Everything seems valueless now... Leaves have to fall someday when it is time." (IDI 14, a 29-year-aged female, Homemaker).

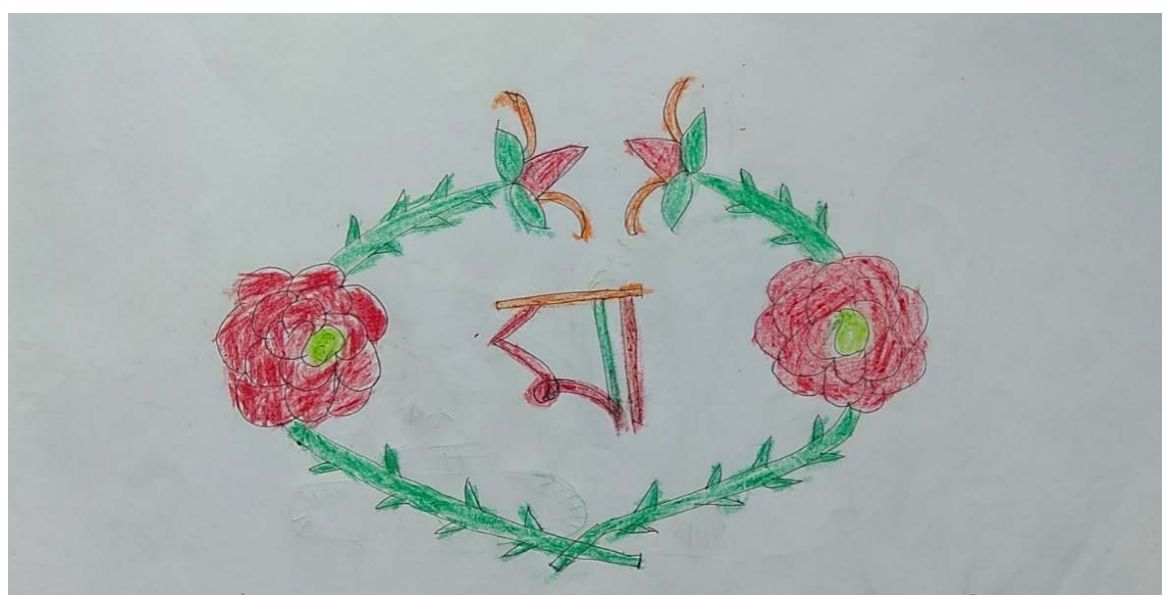

Figure 4. An example of emotions expressed in art. "I love my mother, I also love flower. My mother used to love me a lot. As flower spreads love, my mother used to love me like that... When I was a child during sickness she used to take care of me and pamper me, but now in this condition of mine I miss her." (IDI 02, a 52-year-aged male, Unemployed).

struggles and traumatic experiences from past through their art [3].

\subsubsection{Stronger Insight and Comprehension}

Insight and comprehension include the ability to understand oneself and others through perception and interpretation of the behavior. The patients and carers were able to their emotions into pictures and put forward into words. They mentioned that AT gave them an opportunity to think more about what to draw and which emotions to portray. The carers on the other hand understood their own feelings along with the emotions of the patients and reflected in their arts. Figure 5 


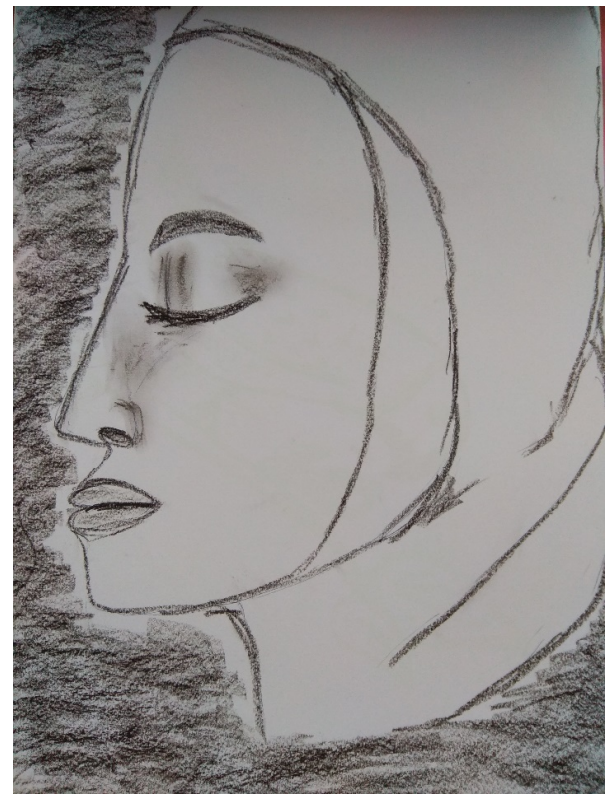

Figure 5. An example of personal self image. "I have seen female patients cover their head by Orna or head scarves as they have less hair or shaved head because of cancer. Unlike male patients, female patients tend to feel insecure because of their appearance. Even if they feel uncomfortable to cover their head all the time, some of them still wear scarves as they say they don't want others to know." (IDI 26, a 24-year-aged female, Health Counselor).

demonstrates this. One of the carers reflected patient's inner struggles that were observed in the following quotes.

Both the patients and carers after AT were able to draw conclusions on their emotions, process and on the art materials as well. 19 out of 25 participants mentioned that they want to continue the AT session whereas some also suggested other psycho-therapies and some entertainment programs should also be conducted for them in the future programs. One of the carers mentioned,

"We can arrange some entertainment programs to improve their physical and psychological well-being for the patients and the cares. Programs like 'Healing through art helped them a lot to express their feeling and also gave them a mode of entertainment." (IDI 27, a 25-year-aged male, Health Counselor)

Through AT patients learned to express their non-verbal experiences into words. A similar finding was showed in the qualitative study with personality disorder [3]. Our study showed the majority of both patients and carers want to continue AT, while an interdisciplinary research team conducted a study and also showed that majority of their participants appreciated the sketchbooks and pencils and wanted to continue AT continue drawing or painting [20].

\section{Limitations}

Since this study is a record review study, there might be some information bias as information was not collected via direct observation and functional analysis. The information obtained might not be complete to be generalizable. Another 
limitation of this study is that it did not consider the treatment phase of the patients who were undergoing frequent chemotherapies that might create a hurdle in receiving the AT properly. It is difficult to determine through this study whether art therapy benefitted the patients or they have been distracted temporarily from the distresses since $\mathrm{AT}$ as an intervention may have a placebo effect.

\section{Conclusion and Recommendation}

This study offers an overview of the potential benefits of AT in the life of cancer patients and their carers. The evidence from this study indicates that patients and carers felt good during AT and majority of them wants to continue AT along with other psychotherapies. There was a reduction in distresses like stress, anxiety and tension and an improvement in the communication skill. Further prospective studies should be conducted to see the effect of art therapy on the quality of life of the patients and their carers. Moreover, studies should be done with the cancer patients and their carers along with the presence of a trained art therapist. Health practitioners should be aware of the fact that AT as a psychotherapy can be beneficial for the cancer patients and can help to add life to their days.

\section{Acknowledgements}

We are grateful to Prof. Nezamuddin Ahmed, Bangabandhu Sheikh Mujib Medical University (BSMMU) for allowing us to work with the records of the patients who were admitted in BSMMU.

Special thanks to Artist Kuhu and SHAKO foundation with eight female artistes for supporting the Art Therapy concept and helping with awareness and Advocacy campaign.

We would like to thank Shubhro of Red Dot Multi Media, ACI conglomerate and Dhaka Bank for supporting the video.

\section{Conflicts of Interest}

The authors declare no conflicts of interest regarding the publication of this paper.

\section{References}

[1] Malchiodi, C.A. (2011) Handbook of Art Therapy. Guilford Press, New York.

[2] American Art Therapy Association (2017) About Art Therapy. Document on the Internet. https://arttherapy.org/about-art-therapy

[3] Haeyen, S., van Hooren, S. and Hutschemaekers, G. (2015) Perceived Effects of Art Therapy in the Treatment of Personality Disorders, Cluster B/C: A Qualitative Study. The Arts in Psychotherapy, 45, 1-10. https://doi.org/10.1016/j.aip.2015.04.005

[4] Wood, M.J.M. (2015) The Contribution of Art Therapy to Palliative Medicine. In: Cherny, N., et al., Eds., Oxford Textbook of Palliative Medicine, Fifth Edition, Oxford University Press, Oxford, 1063-1068. https://doi.org/10.1093/med/9780199656097.003.0411 
[5] Deane, K., Fitch, M. and Carman, M. (2000) An Innovative Art Therapy Program for Cancer Patients. Canadian Oncology Nursing Journal, 10, 147-151. https://doi.org/10.5737/1181912x104147151

[6] Hussain, S.A. and Sullivan, R. (2013) Cancer Control in Bangladesh. Japanese Journal of Clinical Oncology, 43, 1159-1169. https://doi.org/10.1093/jjco/hyt140

[7] Bultas, M.W., Saini, S., Marty, J. and Hendricks-Ferguson, V.L. (2017) Art Making from the HEART: A Pediatric Case Study about Coping and Distraction During Oncology Treatments. Journal of Hospice \& Palliative Nursing, 19, 565-570.

[8] Wood, M.J.M., Low, J., Molassiotis, A. and Tookman, A. (2013) Art Therapy's Contribution to the Psychological Care of Adults with Cancer: A Survey of Therapists and Service Users in the UK. International Journal of Art Therapy, 18, 42-53. https://doi.org/10.1080/17454832.2013.781657

[9] Lin, M.H., Moh, S.L., Kuo, Y.C., Wu, P.Y., Lin, C.L., Tsai, M.H., Chen, T.J. and Hwang, S.J. (2012) Art Therapy for Terminal Cancer Patients in a Hospice Palliative Care Unit in Taiwan. Palliative \& Supportive Care, 10, 51-57. https://doi.org/10.1017/S1478951511000587

[10] Lefèvre, C., Ledoux, M. and Filbet, M. (2016) Art Therapy among Palliative Cancer Patients: Aesthetic Dimensions and Impacts on Symptoms. Palliative \& Supportive Care, 14, 376-380. https://doi.org/10.1017/S1478951515001017

[11] Acid Survivors Foundation (2013) An Expressive Art Therapy Workshop Held with Acid Survivors. Document on the Internet.

http://www.acidsurvivors.org/Event-Details/Event/An-Expressive-Art-Therapy-wor kshop-held-with-Acid-Survivors

[12] Mahboob, D. (2016) Art for Health. Document on the Internet. http://www.dhakatribune.com/feature/2016/10/26/art-for-health

[13] Slayton, S.C., D’Archer, J. and Kaplan, F. (2010) Outcome Studies on the Efficacy of Art Therapy: A Review of Findings. Art Therapy, 27, 108-118. https://doi.org/10.1080/07421656.2010.10129660

[14] Guest, G., Bunce, A. and Johnson, L. (2006) How Many Interviews Are Enough? An Experiment with Data Saturation and Variability. Field Methods, 18, 59-82. https://doi.org/10.1177/1525822X05279903

[15] Lindsey, H. (2006) Pilot Study: Art Therapy Can Reduce Cancer-Related Pain \& Anxiety. Oncology Times, 28, 14. https://doi.org/10.1097/01.COT.0000294391.48547.79

[16] Walsh, S.M., Martin, S.C. and Schmidt, L.A. (2004) Testing the Efficacy of a Creative-Arts Intervention with Family Caregivers of Patients with Cancer. Journal of Nursing Scholarship, 36, 214-219. https://doi.org/10.1111/j.1547-5069.2004.04040.x

[17] Luzzatto, P., Sereno, V. and Capps, R. (2003) A Communication Tool for Cancer Patients with Pain: The Art Therapy Technique of the Body Outline. Palliative \& Supportive Care, 1, 135-142. https://doi.org/10.1017/S1478951503030177

[18] Camic, P. and Knight, S. (2004) Clinical Handbook of Health Psychology: A Practical Guide to Effective Interventions. Hogrefe Publishing, Boston.

[19] Bilgin, E., Kirca, O. and Ozdogan, M. (2018) Art Therapies in Cancer-A Non-Negligible Beauty and Benefit. Journal of Oncological Sciences, 4, 47-48. https://doi.org/10.1016/j.jons.2017.12.003

[20] Nainis, N.A. (2008) Approaches to Art Therapy for Cancer Inpatients: Research and Practice Considerations. Art Therapy, 25, 115-121. https://doi.org/10.1080/07421656.2008.10129597 